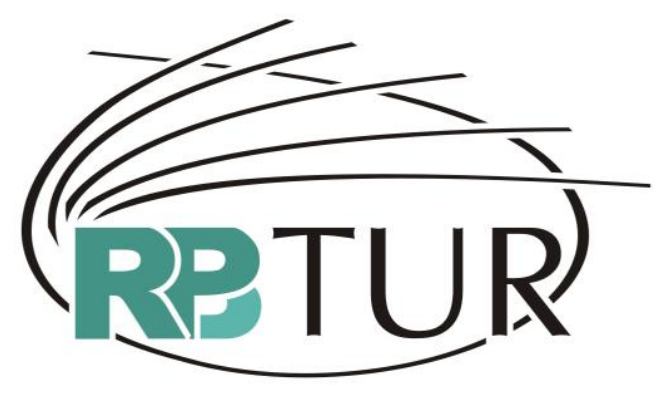

REVISTA BRASILEIRA DE PESQUISA EM TURISMO

\title{
WORKSHOP INTERNACIONAL TURISMO E GESTÃO DO PATRIMÔNIO ARQUEOLÓGICO
}

\author{
WORKSHOP ON INTERNATIONAL TOURISM AND \\ ARCHAEOLOGICAL HERITAGE MANAGEMENT
}

\section{TALLER SOBRE TURISMO INTERNACIONAL Y GESTIÓN DEL PATRIMONIO ARQUEOLÓGICO}

\author{
Silvio Lima Figueiredo ${ }^{1}$ \\ Edithe da Silva Pereira ${ }^{2}$ \\ Marcia Bezerra de Almeida ${ }^{3}$
}

O estudo da gestão no turismo sempre teve papel de destaque, não só nas combinações e ações da racionalidade de empresas de tipos variados, desde operadoras turísticas, até hotéis e hospitalidade como um todo. A gestão pública, da formulação de políticas à implementação de programas e projetos não foge à regra e as áreas onde são desenvolvidas as atividades turísticas necessitam da organização de sua gestão e de seu funcionamento, assim como os recursos a disposição do turismo: elementos da cultura e da natureza percebidos como patrimônio cultural e natural. Por outro lado, os

\footnotetext{
${ }^{1}$ Doutor em Comunicação pela Universidade de São Paulo. Professor/pesquisador do Programa de Pós-Graduação em Desenvolvimento Sustentável do Trópico Úmido do Núcleo de Altos Estudos Amazônicos da Universidade Federal do Pará, Brasil. E-mail: slima@ufpa.br

${ }^{2}$ Doutora em Arqueologia pela Universidade de Valência, Espanha. Pesquisadora do Museu Paraense Emilio Goeldi, Brasil. E-mail: edithepereira@museu-goeldi.br

${ }^{3}$ Doutora em Arqueologia pela Universidade de São Paulo. Professora e Pesquisadora da Faculdade de Ciências Sociais, Universidade Federal do Pará, Brasil. E-mail: mar.bezerra@uol.com.br
} 
ISSN: $1982-6125$

estudos da arqueologia se deparam cada vez mais com a presença de visitantes nas áreas pesquisadas, os sítios arqueológicos. Como patrimônio de um povo ou de uma comunidade, esses sítios vêm recebendo cada vez mais a atenção de profissionais das áreas do turismo e da arqueologia na tentativa de propor sistemas de visitação e, por conseguinte, de uso turístico e mercadológico de sítios de vários tipos, tais como sítios com arte rupestre, os sítios megalíticos, tesos, sambaquis e ruínas de sítios históricos, entre outros. Para debater esses temas a partir de experiências do que tem sido chamado de "socialização de sítios arqueológicos", e propor novos modelos teóricometodológicos para a sua gestão, realizou-se o "Workshop Internacional Turismo e Gestão do Patrimônio Arqueológico", de 28 a 30 de abril de 2009, no Museu Paraense Emílio Goeldi na cidade de Belém, Estado do Pará, Brasil.

O evento foi organizado a partir de três eixos principais: 1) discussão teórico-metodológica sobre a socialização de sítios, a partir da implementação de ações de musealização, sinalização, gestão da visitação e capacidade de carga, variáveis arqueológicas, museologia e museografia, estudo do contexto e da paisagem integral; 2) apresentação de experiências de socialização de sítios arqueológicos em Portugal, Argentina e Brasil: Rio Grande do Sul, Goiás e Piauí e 3) apresentação de três sítios arqueológicos, localizados nos Estados do Pará e Amapá, para os quais estão sendo elaborados projetos executivos de musealização e socialização financiados pela $2^{a}$ Regional do Instituo do Patrimônio Histórico e Artístico Nacional/IPHAN.

Abrindo as apresentações da parte do evento, Silvio Lima Figueiredo, professor e pesquisador do Núcleo de Altos Estudos Amazônicos da Universidade Federal do Pará (UFPA) e coordenador do evento e da pesquisa "Turismo em Unidades de Conservação: arqueologia e turismo no Parque Estadual da Serra dos Martírios/Andorinhas, Pará" demonstrou durante a apresentação do trabalho "Turismo, Visitação e Uso Público do Patrimônio Natural e Cultural", algumas possibilidades de musealização de sítios 
arqueológicos para implantação de estruturas e projetos executivos, modelos de gerenciamento de sítios e das unidades nas quais eles estão situados, uso de capacidade de carga com variáveis arqueológicas como grau de fragilidade, grau de importância arqueológica e visualização, zoneamento específico e análise da paisagem/contexto do sítio. Nessa primeira parte também foi apresentada discussão sobre outros itens da socialização dos sítios arqueológicos, como a educação patrimonial, importante nas ações socializadoras. Em seguida, a arqueóloga e professora da Universidade Federal do Pará, Marcia Bezerra, também coordenadora do evento, iniciou uma discussão, considerando as percepções sobre a relação entre comunidades locais, visitantes e o patrimônio arqueológico, durante a apresentação do trabalho "Arqueologia, Turismo e Comunidades Locais: reflexões de um 'Turista Aprendiz' ". A pesquisadora levantou algumas questões sobre o papel das ações pedagógicas na sensibilização das comunidades locais e dos visitantes, a partir da Educação Patrimonial, com base na sua experiência em projetos desenvolvidos na Ilha do Marajó.

A segunda parte do evento foi marcada pela exposição de experiências de socialização de sítios arqueológicos em Portugal, Argentina e Brasil, particularmente, o Rio Grande do Sul, Goiás e Piauí. A experiência em Portugal apresentada por Manuel Calado, da Universidade de Lisboa, tratou da musealização de sítios megalíticos nas proximidades da cidade de Évora, localizada no centro do país. Os exemplos contemplados pelo arqueólogo, os sítios megalíticos dos Almendres e o Murteiras, estão localizados em áreas privadas, com sinalização, estruturas para facilitar a visitação e sobretudo, ações importantes de animação sócio-cultural e Educação Patrimonial no auxilio à preservação dos locais. As visitas aos sítios têm o apoio do Centro de Megalitismo de Évora, na sua interpretação e na atuação junto às comunidades locais e aos habitantes da zona urbana. Na apresentação intitulada "Turismo em sítios megalíticos atlânticos: a experiência portuguesa, no quadro da União 
ISSN: $1982-6125$

Européia", Manuel Calado relatou a intensa participação dos habitantes das áreas próximas aos sítios e das cidades do entorno em ações de preservação desses sítios, tais como a recolocação dos menires na sua posição original, realizada pelos moradores, com o acompanhamento de arqueólogos e engenheiros. Essa exposição sublinhou a importância da atividade turística planejada na conservação e na divulgação dos sítios arqueológicos.

A arqueóloga argentina Mercedes Podestá, do Instituto Nacional de Antropología y Pensamiento Latinoamericano da Argentina (INAPL), apresentou no trabalho "Itinerarios Rupestres: Un debate sobre la incorporación de sitios con arte rupestre a la gestión turística en Argentina", a experiência do uso turístico e da gestão da visitação de alguns sítios de arte rupestre na Argentina, considerando conceitos de Arqueoturismo e fazendo um breve panorama mundial do tema. A pesquisadora ainda analisou o programa "Documentación y Preservación del Arte Rupestre Argentino" (DOPRARA), a partir de estudos de caso no vale inferior do rio Manso e na Cueva de las Manos del Río Pinturas, ambos na Patagônia Argentina, no Parque Provincial Ischigualasto e a participação da comunidade em Los Colorados e o fechamento das Cuevas Pintadas de Las Juntas em decorrência da destruição e pichação do patrimônio.

O segundo dia do encontro teve início com a apresentação, "Proteção e conservação de Sítios Arqueológicos no Parque Nacional Serra da Capivara" que abordou a experiência da Universidade Federal de Pernambuco, da Fundação Museu do Homem Americano e de outras instituições na preservação e uso público do Parque da Serra da Capivara. O trabalho apresentado pela arquiteta Elizabete Buco (FUMDHAM) sobre uma das mais representativas experiências de conservação e visitação de sítios no Brasil, mostrou a necessidade da existência de um Plano de Manejo bem elaborado e executado, levando em consideração os principais fatores de destruição e depredação e os 
ISSN: 1982-6125

estudos que determinaram as formas de instalação das estruturas de visitação e de conservação dos sítios.

As missões jesuíticas guaranis do Rio Grande do Sul foram tema da exposição "Socialização dos sítios das Missões Jesuítico-Guarani - RS", da pesquisadora Ana Lúcia Meira, do IPHAN gaúcho. Todo o processo de conservação e musealização das ruínas das missões jesuíticas foi detalhado, tendo a autora enfatizado que a socialização só se efetiva quando inserida em um escopo de ações de proteção, conservação e valorização integradas, que sejam garantidas por políticas públicas efetivas, além de ter a comunidade como parceira. A gestora citou exemplos ligados à criação da Associação dos Amigos das Missões, à inclusão de universitários a partir de projetos de pesquisa e extensão, e às ações de integração com a comunidade MbyáGuarani, que vive próxima às ruínas durante determinados períodos do ano.

Essa segunda parte do evento foi encerrada com a apresentação da pesquisadora Mariza Barbosa, da Universidade Católica de Goiás, denominada "Turismo Arqueológico no Sudoeste do Estado de Goiás: relatos e experiências", que contemplou as tentativas de musealização dos sítios de arte rupestre de Serranópolis (GO) e de Palestina de Goiás (GO), ambos com problemas de gestão, inclusive com intervenção de pichações nas pinturas. No caso de Serranópolis conseguiu-se evitar o agravamento dos problemas e hoje há visitação regular aos sítios em razão de seu gerenciamento por empresa ligada ao turismo, neste caso, uma pousada.

A terceira parte do evento se caracterizou pela apresentação das três áreas que receberão os projetos executivos para a musealização e socialização no estado do Pará e do Amapá, em uma ação desenvolvida pela $2^{a}$ Regional do Iphan. São eles: os sítios com pinturas rupestres de Monte Alegre, no Parque Estadual Monte Alegre (Pará); o sítio "megalítico" de Calçoene, e os sítios cerâmicos de Maracá (ambos no Amapá). A mesa redonda "Breve discussão dos sítios de Monte Alegre, Calçoene e Maracá" reuniu os arqueólogos que 
pesquisaram os sítios em questão. A sessão foi aberta pela arqueóloga, e coordenadora do evento, Edithe Pereira (Museu Paraense Emilio Goeldi), que mostrou as características dos sítios arqueológicos com arte rupestre de Monte Alegre, as nuances das pinturas, as informações arqueológicas disponíveis, as análises do contexto e da paisagem do entorno. Foram observados os principais fatores limitantes à visitação e discutidas as melhores formas de gestão para a visitação do local. A arqueóloga Vera Guapindaia (Museu Paraense Emilio Goeldi) abordou as características dos abrigos de Maracá, no município de Mazagão (AP), famosos por singulares urnas funerárias depositadas nos chamados sítios-cemitérios (grutas e abrigos). Segundo a pesquisadora, existem dois tipos de urnas: as antropomorfas, que representam uma figura humana sentada em um banco com as mãos apoiadas nos joelhos; e as zoomorfas, que representam um animal quadrúpede em pé. As possibilidades de musealização desses sítios são mais difíceis, embora apresentem maiores possibilidades de situações para a sua interpretação. 0 sítio de Calçoene foi apresentado pelos arqueólogos João Saldanha e Mariana Cabral, do Instituto de Pesquisas Científicas e Tecnológicas do Estado do Amapá (IEPA). Os pesquisadores mostraram os diversos blocos de granito, dispostos de forma circular, fincados no solo em sentido vertical, com datação ainda desconhecida e significados provavelmente ligados a observações astronômicas. O sítio possui um valioso potencial para o turismo, dada a relação sítio/paisagem, a disponibilidade de informação arqueológica e pelo fato de ser o maior sítio de megalítico das Américas. Foram lançadas propostas de gestão e de uso turístico da área.

Em encontro posterior no dia 30, a equipe responsável pelo projeto se reuniu para aprofundar as discussões e propor os modelos de gestão que serão pormenorizados nos projetos executivos. Como considerações finais, foi possível perceber a importância do estudo teórico-metodológico da gestão de patrimônio cultural e natural para o turismo, aliados à paisagem, visando a 
FIGUEIREDO, Silvio Lima; PEREIRA, Edithe da Silva; ALMEIDA, Marcia Bezerra de. Workshop Internacional Turismo e Gestão do Patrimônio Arqueológico. Revista Brasileira de Pesquisa em Turismo v. 3, n. 2, p. 95-101, ago 2009.

ISSN: $1982-6125$

exploração turística desse patrimônio e, ao mesmo tempo, contribuindo para sua preservação e para projetos de desenvolvimento sustentável que envolvam os sítios arqueológicos e as comunidades que habitam o seu entorno. Os trabalhos aqui enfocados serão publicados em livro a ser lançado pelo IPHAN.

Recebido em agosto 2009.

Aprovado em agosto 2009. 